\title{
Engagement-focused care during transitions from inpatient and emergency psychiatric facilities
}

\author{
This article was published in the following Dove Press journal: \\ Patient Preference and Adherence \\ 12 May 2017 \\ Number of times this article has been viewed
}

\section{Dawn I Velligan \\ Megan M Fredrick \\ Cynthia Sierra \\ Kiley Hillner \\ John Kliewer ${ }^{\dagger}$ \\ David L Roberts \\ Jim Mintz}

Department of Psychiatry, University of Texas Health Science Center San Antonio, San Antonio, TX, USA

†Dr John Kliewer passed away on April 5, 2017
Correspondence: Dawn I Velligan

University of Texas Health Science

Center San Antonio, 7703 Floyd Curl

Drive, Mail Stop 7797, San Antonio, TX

78229, USA

Tel + I 2105675508

Fax +| 210567 |29|

Email velligand@uthscsa.edu
Objectives: As many as $40 \%$ of those with serious mental illness (SMI) do not attend any outpatient visits in the 30 days following discharge. We examined engagement-focused care (EFC) versus treatment as usual in a university-based transitional care clinic (TCC) with a 90-day program serving individuals with SMI discharged from hospitals and emergency rooms. EFC included a unique group intake process (access group) designed to get individuals into care rapidly and a shared decision-making coach.

Methods: Assessments of quality of life, symptomatology, and shared decision-making preferences were conducted at baseline, at 3 months corresponding to the end of TCC treatment and 6 months after TCC discharge. Communication among the patients and providers was assessed at each visit as was service utilization during and after TCC.

Results: Subjective quality of life improved in EFC. Prescribers and patients saw communication more similarly as time went on. Ninety-one percent of patients wanted at least some say in decisions about their treatment.

Conclusions: SDM coaching and improved access improve quality of life. Most people want a say in treatment decisions.

Keywords: shared decision making, mental illness, community mental health, patient education

\section{Introduction}

For individuals with serious mental illness (SMI), timely access to community services at discharge from hospital or emergency departments is particularly critical. ${ }^{1,2}$ In fact, costs for SMI are an estimated $\$ 317$ billion annually in the USA. ${ }^{3}$ This translates to an estimated $\$ 1,000$ per year for every man, woman, and a child in the USA. ${ }^{3}$ As the health care system moves progressively toward a "pay for performance" reimbursement model, it will become increasingly important to ensure continuity of care and engagement in the long-term management of these illnesses. Coordination between inpatient and outpatient clinics increases initial outpatient attendance, and case management can improve this coordination. ${ }^{4-9}$ However, beyond this, little is known about post-acute psychiatric transitional care. In particular, it is not known whether transitional services can affect patients' long-term engagement in care, attitudes toward care, or empowerment as health care consumers.

In April 2012, we launched a novel transitional care clinic (the TCC) for post-acute psychiatric patients in Bexar County (San Antonio), Texas, with the goal of improving linkage to outpatient care and improving engagement in maintenance mental health care through patient-centered services. The TCC is designed to offer more rapid intake and access to services than the local community mental health service system and provides treatment for up to 90 days until the individual can be connected to existing services. Services include medication management, care coordination, and a variety of 
evidence-based psychotherapies. ${ }^{10}$ Treatment ends with ensuring that the person makes a successful transition to longer-term facilities in the community.

In this context, we examined a traditional standard care (SC) approach versus engagement-focused care (EFC) during transition for individuals with SMI. EFC had two components not typically found in transitional care models: 1) an access group intake process and 2) shared decision-making (SDM) coaching for patients. ${ }^{11}$

The impetus for access group in which up to eight patients are seen together versus individual intake was the need to get individuals into intake appointments as rapidly as possible. When individual intakes are scheduled with show rates hovering below 50\%, slots fill quickly and patients end up being scheduled out months following discharge. In the mean time they have no access to a psychiatrist or other prescribers to refill medications and are presenting at emergency services and inpatient facilities. Moreover, the access group process allows the TCC to prioritize patient needs. For example, some individuals have not filled a prescription they received from the hospital because they cannot pay for medication. A social worker is their most immediate need to assist them with getting their medication as soon as possible. Other patients come from emergency rooms where they were not prescribed medications; many of these individuals need an appointment with a psychiatrist or other prescriber as soon as possible. Still other individuals are heading into crisis and need rapid access to appointments for psychotherapy. The access group process allows needs to be prioritized and each person to get what they need most as quickly as possible. Recent research at the TCC suggested that while individual intakes are rated slightly more favorably by patients, both services are rated good or better and patients are very willing to have an access group if it decreases the wait for services. ${ }^{10}$

SDM was included to improve patient engagement. SDM is rarely used in transitional programs. Patients who feel they are playing an active role in their treatment typically have better engagement and outcomes than patients who experience themselves as passive recipients of care. ${ }^{12-14}$ Unfortunately, across diagnoses and conditions, patients more typically engage with providers in a passive manner, and lack of engagement is related to poor follow-through with prescribed regimens. ${ }^{15,16}$ Poor treatment follow-through has severe consequences for individuals immediately following hospitalization or crisis care, often leading to recidivism and decreased quality of life. ${ }^{17}$

The use of SDM in psychiatry has received support through the New Freedom Commission on Mental Health (2003), and other recent government policy reports. ${ }^{18-21}$ SDM may be of particular benefit in SMI because of the high incidence of poor treatment follow-through. SDM represents a nonthreatening approach to clarifying motivations and options for improving quality of life. Adults with SMI frequently make competent and prudent treatment decisions. ${ }^{22,23}$ Also, despite some behavioral passivity, patients with SMI express strong desire to be informed about their illness and treatment options, and to be active participants in their treatment decisions, a slightly higher desire than expressed by patients in primary care. ${ }^{24-28}$ Patients making the transition from hospital to community care want to be active participants and get more information about illness and treatments than they are currently getting. ${ }^{10}$

We hypothesized that individuals in EFC would be more likely to attend their TCC intake appointment than those in SC. We hypothesized that those in EFC would report significantly greater SDM in their TCC psychiatrist/prescriber visits, greater attendance at post-intake appointments, greater attendance at post-TCC mental health follow-up appointments, and greater quality of life than those in SC. Primary outcomes were patient-reported quality of life and attendance at mental health services postdischarge.

\section{Methods}

\section{Setting}

The study was conducted in a university-run TCC funded in part by a charitable grant from the Methodist Health Care Ministries and by a Medicaid 1115 Waiver. The research study was reviewed and approved by the University of Texas Health Science Center San Antonino's Institutional Review Board. The TCC was designed to address a shortage of providers resulting in patients being rehospitalized and getting repeated care from emergency departments. The TCC provides treatment for up to 90 days until the individual can be connected to existing long-term services. The TCC initially received referrals from two area inpatient psychiatric hospitals and emergency departments, but early in this trial, this rapidly expanded to eight area hospital and emergency departments in Bexar County.

\section{Design}

Prior to the start of randomization, all physicians and residents at the TCC were trained in SDM in a 1.5-day seminar. This session was taped and 1-hour refreshers on SDM were held at least once every 6 months during the trial.

In this comparative effectiveness trial, there were two phases of recruitment. In the first phase, patients were recruited at the hospitals referring to TCC. Due to significant logistical problems with this, including opening TCC referrals to many more facilities, and many patients signing consent 
never attending the TCC, we began recruiting just prior to the TCC intake at the TCC. Because of this change in recruitment, our first hypothesis regarding show rates at intake could be examined only with the first recruiting phase in a subset of patients. For recruitment in the hospital, patients were approached by university research staff credentialed at participating sites in accordance with the Health Insurance Portability and Accountability Act (HIPAA) requirements, told about the program, and asked to sign informed consent. They were then randomized using a computer program that scheduled them for SC or EFC. For recruitment at the TCC, patients were approached by research staff after a group orientation to the clinic and asked if they would verbally consent to randomization into individual or access group. Following the intake, the ones who had agreed verbally to randomization were then asked if they would be willing to consent to the study as a whole including all assessments and the SDM component if offered. All participants signed a written consent form approved by the University of Texas Health Science Center's Institutional Review Board, and procedures were consistent with internationally recognized standards for ethical conduct of human research. Randomization was 2:1 EFC:SC due to resource availability for individual intakes.

All patients received medication follow-up, case management, in-home services, and psychotherapy as recommended by their intake and treatment team. After intake, individuals were given a baseline assessment and followed for $\sim 9$ months. Formal assessments were repeated at 3 months (the modal treatment termination time at the TCC) or TCC discharge and 6 months following discharge from the TCC. In addition, attempts were made at each visit with a psychiatrist or other prescriber to have both patients and providers rate the process of the visit. Finally, calls to track service utilization after discharge from the TCC were made monthly.

\section{Participants}

One thousand three hundred seventy-seven individuals who were consecutive admissions (to psychiatric units [ $\mathrm{n}=45]$ or to the TCC following hospital discharge $[\mathrm{n}=1,332])$ were approached for participation from 08/2014 to 11/2015. Of these 1,377, 465 signed informed consent. All patients were over the age of 18 , had SMI, and were able to give informed consent. There were no exclusion criteria.

\section{Treatment groups}

\section{Standard care}

An individual intake was conducted post-hospital discharge, and a follow-up appointment with a prescriber was scheduled for a first available slot, $\sim 1$ week following intake. Medication management, group and individual psychotherapy, care coordination, and access to home visits to assist with medication management and daily structure were provided as needed.

\section{Engagement-focused care}

Patients participated in access group post-hospital discharge to accommodate individual needs. Multiple patients (up to 17 per day) were scheduled at the same time and date using a HIPAA-compliant, web-based referral system that allows hospital staff to give appointments and upload collateral. Patients who showed up for their appointment participated in a brief orientation to the clinic (making appointments, parking, and so on) conducted by a patient navigator. Meanwhile, the access team that typically includes a psychologist or psychology intern, social work student, and medical student read hospital collateral in another room. Next, members of the access team met with a small group of patients $(n=3-8)$, speaking individually to each member for 5-10 minutes depending upon the size of the group to understand reasons for hospitalization and hospital course, to determine current needs, and make a preliminary patientdirected plan. Following the group, while patients remained in the group room, the access team met in another room together with a scheduler to make appointments that were discussed with patients for all TCC services. Same-day appointments with prescribers were available for those in most acute need and others received appointments based upon the amount of medication they had left and clinical considerations (eg, medication not working well). Patients were then checked out individually, which is usually a 5-minute process to go over the plan. This procedure is described in detail elsewere. ${ }^{10}$

\section{SDM coaching}

Also included in EFC was an SDM coach who met with the patient prior to and sometimes following appointments with the prescriber. Visits lasted anywhere from 15 minutes to an hour depending upon needs and patient availability. The coach worked with the patient to identify goals for their session with the prescriber and helped them learn a simple acronym for their role called TAC-Review (Tell, Ask, Choose, Review and Research). The coach role-played with the patient difficult-to-discuss topics and offered access to videos of patients with similar conditions and SDM tools that identify the pros and cons of different treatments.

All individuals in EFC received medication follow-up and other services based on need similar to those in SC. 


\section{Assessments Quality of life}

Quality of life was measured by the Quality of Life Interview (QOLI). ${ }^{29}$ The QOLI is a 45-minute structured interview that assesses subjective satisfaction and objective factors (ie, functioning, access to resources) in the domains of family, social relations, leisure activities, finances, legal/ safety issues, work/school, and health. It is one of the most psychometrically sound instruments for assessing quality of life in mental illness. ${ }^{30} \mathrm{We}$ examined the mean of all subjective items to emphasize the patient perspective as one of our primary outcome variables.

\section{Treatment engagement}

There is low consensus on definition and measurement of treatment engagement. ${ }^{31,32}$ Our primary metric was behavioral attendance at treatment appointments because this can be reliably measured and is correlated with clinical change. ${ }^{33,34}$ Our primary measure of treatment engagement was attendance at mental health visits postdischarge from the TCC. Other metrics for engagement were also examined. For individuals recruited at the hospital (Phase I of recruiting) we examined the proportion in each group that came to their initial intake appointment. For all patients we examined engagement by looking at the proportion of postintake appointments kept versus those scheduled for all services at the TCC (other than SDM coaching visits) based upon data from the electronic medical record.

\section{Symptomatology}

To characterize the sample and examine changes in symptoms over time we used the Expanded Brief Psychiatric Rating Scale (BPRS), ${ }^{35}$ a 24-item interview-based measure that captures a range of psychiatric symptoms rated on 7-point Likert scales. These scales are summed to yield a total score.

\section{Insight}

Insight was assessed using the abridged Scale to Assess Unawareness of Mental Disorder (SUMD) ${ }^{36}$ consisting of the items assessing awareness of having a mental disorder, awareness of the need for medication, and awareness of social consequences resulting from any mental disorder. Lower scores indicate better insight into these aspects of the illness.

\section{Service utilization}

Monthly calls to patients were conducted using a brief version of an interview adapted from the NIMH Epidemiologic
Catchment Area Program ${ }^{37}$ and the HIV Cost and Services Utilization Study.$^{38}$ This abridged version of the survey has been used in multiple published studies. ${ }^{39,40}$ Rates of negative service utilization outcomes including rehospitalization for mental health, presentation at emergency or crisis services for mental health, and incarceration were examined by treatment group based upon monthly calls. All occurrences of these events were totaled for each patient across the follow-up period.

\section{Shared decision making}

Measurement of SDM is complex because it involves two parties, their interaction, and their perceptions of one another. Additionally, there are individual differences in the degree of information and participation that patients prefer, and, in psychiatry in particular, symptom experiences and cognitive deficits may affect patients' ability to participate in SDM independent of their desire or the skill of the practitioner. For these reasons, aspects of SDM were assessed using several measures.

\section{Control preferences scale}

Patient preference for participation in the SDM was assessed at baseline and follow-up using the Control Preferences Scale (CPS) ${ }^{41}$ This scale presents patients with five cards that each present a statement describing a different role in decision making. Statements include: 1) I prefer to make decisions about which treatment I receive; 2) I prefer to make the final decision about my treatment after seriously considering my doctor's opinion; 3) I prefer that my doctor and I share responsibility about which treatment is best for me; 4) I prefer that my doctor makes the final decision about which treatment will be used but seriously considers my opinion; 5) I prefer to leave all decisions regarding my treatment to my doctor. Cards are presented to the patient in pairs in a prespecified order $(2,4,3,1$, and 5) until the five statements are rank ordered. The reliability and validity of this method have previously been established. ${ }^{41}$

\section{Matched-Pair Instrument}

Patient and prescriber ratings of in-session communication were obtained following visits with the prescriber using the Matched-Pair Instrument (MPI). ${ }^{42}$ The MPI is a dyadic instrument consisting of 19 statements that assess the content and process of a prescriber's communication skills from each member's perspective. Each skill on the MPI is rated on a 5-point scale with higher scores indicating stronger agreement with the statement. A version is completed by the prescriber and 
a version is completed by the patient immediately following the encounter. A difference score between provider and patient ratings was calculated. The absolute value of this score reflected the average distance between patients and providers in their perceptions of communication during the session.

\section{Patient satisfaction and intent to participate in treatment after discharge from the TCC}

All participants completed a face-valid feedback questionnaire addressing various domains of their treatment experience on a series of seven-point Likert-type scales ranging from completely dissatisfied to completely satisfied. Items were adapted from a measure used in a recent study of an SDM decision aid by Woltmann et al. ${ }^{43}$ In addition, patients rated their intent to participate in post-TCC mental health care on a five-point scale ranging from "definitely want future mental health care" to "definitely do not want future mental health care."

\section{Engagement in follow-up care}

Based upon monthly telephone calls, we examined the percentage of patients who participated in mental health treatment in the month following discharge from the TCC versus those who did not.

\section{Treatment blinds}

In an effort to maintain treatment blinds, all participants were asked at the beginning of each assessment not to divulge information about any visits at the TCC. If blinds were broken, alternative raters blind to group assignment completed the remaining assessments.

\section{Data analysis}

We examined distributions for normality and homogeneity of variance and used transformations where necessary to meet the assumptions of the statistical models. In cases where distributions could not be normalized, we used nonparametric statistics. All patients with a baseline assessment and at least one post-baseline assessment were included in intent-to-treat analyses. We examined group differences in subjective quality of life, BPRS symptomatology, satisfaction with treatment, and difference scores on the MPI over time (3 months and 6 months post-treatment) by treatment group (EFC, treatment as usual) using mixed-effects regression with repeated measures (SAS PROC MIXED) (SAS 9.3 2011; SAS Institute Inc,. Cary, NC, USA). Baseline scores were used as covariates in the models. For percentage of appointments kept, Wilcoxon tests were used. For count data (eg, service utilization occurrences) $\mathrm{X}^{2}$ testing was used.

\section{Results Dropout and demographics}

Between consent and first assessment, 139 were lost to follow-up and did not participate in the study assessments. Of the 326 participating in assessments, 147 subjects were male and 179 were female. One hundred sixty were Hispanic, 135 were Anglo, 24 were African-American, 3 were Asian, and the remaining individuals were of mixed ethnic background. Mean age of participants was 38.0 (standard deviation $[\mathrm{SD}]=12.0$ ). At baseline, mean level of symptomatology as rated by the expanded version of the BPRS was 53.7 ( mean $=53.7 ; \mathrm{SD}=11.6$ ).

Table 1 presents the demographic and baseline variables by treatment group. There were no statistically significant group differences with respect to demographic or baseline data with one exception. Individuals randomized to EFC were slightly younger than those randomized to SC $(\mathrm{t}=3.92 ; P<0.05)$. There were no significant differences in demographics or symptom variables for participants dropping out after baseline assessments versus those who continued participation and had baseline and at least one follow-up assessment (all $P>0.20$ ) with one exception. The one difference was that a greater percentage of non-Hispanic white participants dropped out before receiving a second assessment than did Hispanic participants (55\% vs $38 \%$; $\left.\mathrm{X}^{2}(1)=6.41 ; P<0.01\right)$.

The consort diagram appears in Figure 1. There was no significant difference between treatment groups with respect to dropout rates following randomization with $31.85 \%$ dropout in $\mathrm{SC}$ and $28.90 \%$ in $\mathrm{EFC}\left(\mathrm{X}^{2}(1)=0.43, P>0.51\right)$.

In EFC, 135 out of 219 patients (62\%) participated in SDM appointments with the coach at least once. A total of

Table I Demographic and outcome variables at baseline

\begin{tabular}{|c|c|c|}
\hline & $\begin{array}{l}\text { Engagement-focused } \\
\text { care }(n=219)\end{array}$ & $\begin{array}{l}\text { Standard care } \\
(n=107)\end{array}$ \\
\hline Mean age & $37.1(\mathrm{SD}=1 \mathrm{I} .4)$ & $39.9(\mathrm{SD}=13.1)$ \\
\hline Male, \% & $44(n=96)$ & $48(n=5 I)$ \\
\hline $\begin{array}{l}\text { Brief Psychiatric Rating Scale } \\
\text { total score }\end{array}$ & $54.0(\mathrm{SD}=12.7)$ & $53.7(\mathrm{SD}=\mathrm{I} \mathrm{I} .6)$ \\
\hline Non-Hispanic white, \% & $4 \mid(n=89)$ & $44(n=46)$ \\
\hline African American, \% & $6(n=14)$ & $10(n=10)$ \\
\hline Hispanic, \% & $52(n=112)$ & $46(n=48)$ \\
\hline Asian, \% & I $(n=2)$ & $I(n=1)$ \\
\hline Other/mixed, \% & I $(n=2)$ & $2(n=2)$ \\
\hline Quality of life mean score & $3.9(\mathrm{SD}=1.1)$ & $3.8(\mathrm{SD}=1.1)$ \\
\hline $\begin{array}{l}\text { Scale to Assess Unawareness } \\
\text { of Mental Disorder mean } \\
\text { score (first } 3 \text { items) }\end{array}$ & $\mathrm{I} .8(\mathrm{SD}=0.9)$ & $1.7(\mathrm{SD}=0.8)$ \\
\hline
\end{tabular}

Abbreviation: SD, standard deviation. 


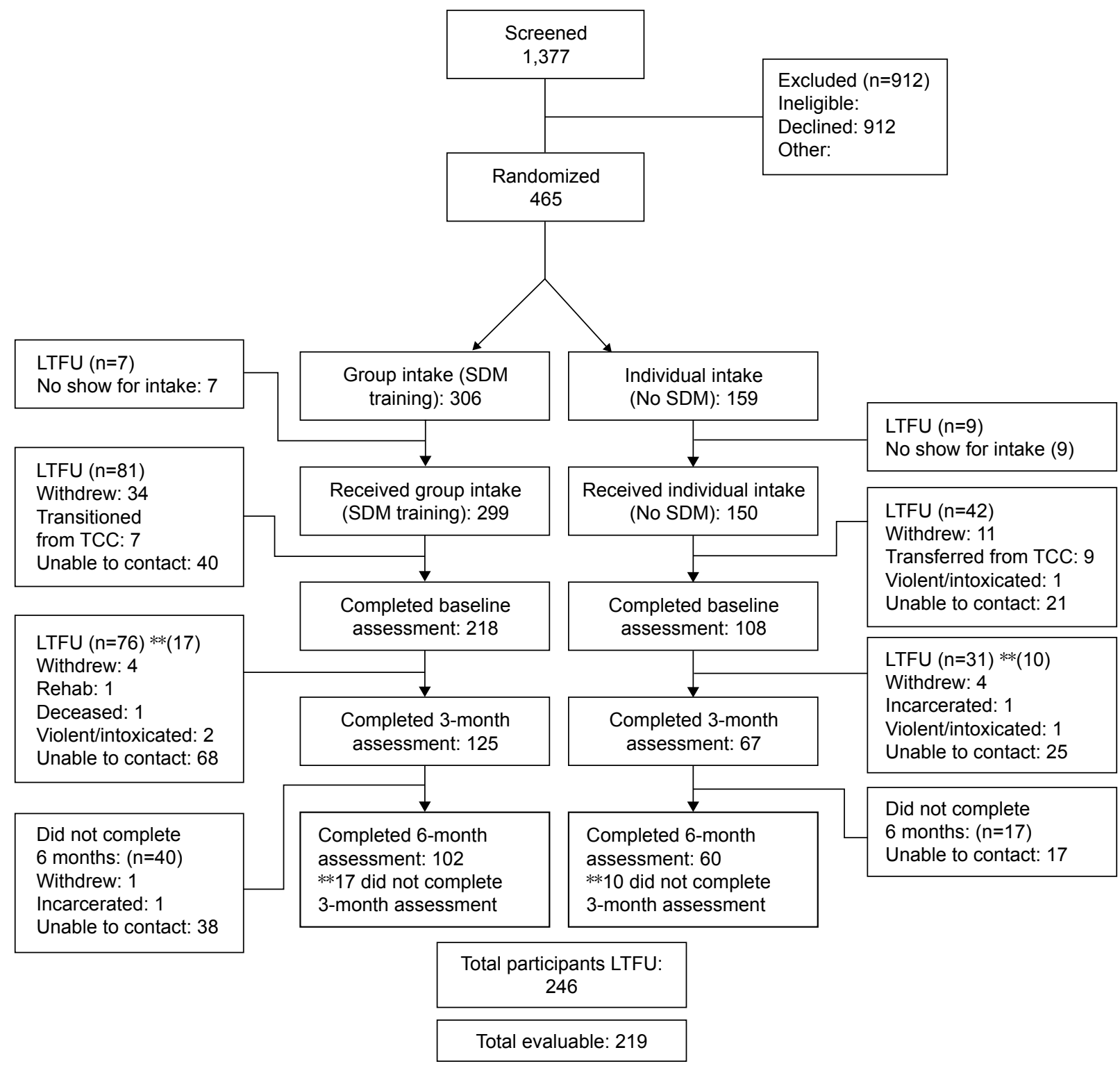

Figure I Consort diagram.

Abbreviations: SDM, shared decision making; TCC, transitional care clinic; LTFU, lost to follow up.

273 visits were delivered. On average, patients in EFC had 28.8 minutes of SDM coaching. Problems in delivery of SDM included that patients did not show up early enough to attend appointments or did not have time to stay after seeing the doctor for SDM appointments. The most common needs patients expressed were for reassurance that the doctor wanted them involved in the decision-making process and role-playing difficult scenarios (eg, discussion of sexual side effects of medication).

\section{Primary outcomes}

\section{Quality-of-Life Inventory}

The mixed-effects regression model examining subjective quality of life from the QOLI yielded significant effects of group $(\mathrm{F}(1,216)=4.14 ; P<0.04)$ and nonsignificant effects of time $(\mathrm{F}(1,132)=2.31 ; P>0.13)$ and group by time $(\mathrm{F}(1,132)=0.32 ; P>0.56)$. An inspection of means indicates greater improvement of quality of life in EFC than in SC with this difference remaining consistent across the follow-up period. Figure 2 depicts means derived at specified time points by treatment group.

\section{Engagement in mental health services}

With respect to engagement in mental health services following treatment at TCC, our primary measure of engagement, we examined data from the first call survey following TCC discharge. Approximately $61 \%$ of all patients were engaged in mental health services following discharge from 

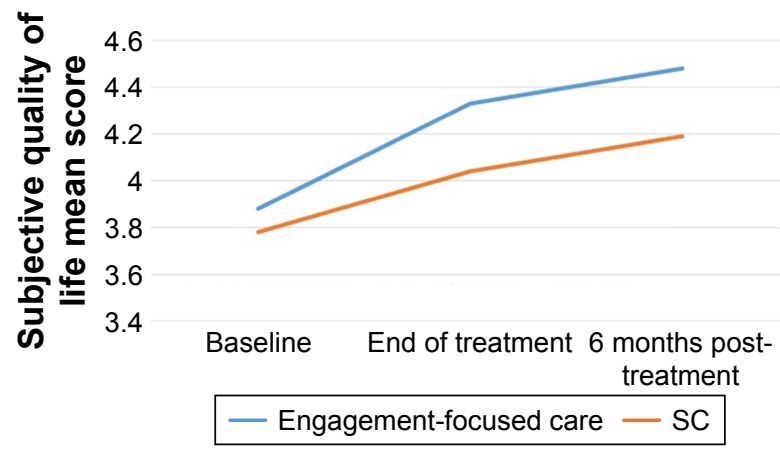

Figure 2 Subjective quality of life over time by treatment group. Abbreviation: SC, standard care.

the TCC. These numbers were nearly identical for both treatment groups and the difference was not statistically significant $\left(\mathrm{X}^{2}(1)=45 ; P>0.50\right)$.

As a secondary measure of treatment engagement we compared the proportion of visits kept while in treatment at TCC by group. Results revealed that in standard treatment $80.4 \%$ ( $\mathrm{SD}=27.5)$ of all appointments were kept and in EFC $85.4 \%$ (SD =22.7) were kept. This difference did not reach statistical significance but there was a strong trend in onetailed testing, which was more in line with the hypothesized results $(P<0.054)$

For the subset of patients recruited from inpatient units we examined the likelihood of presenting to TCC intake by group. Participants scheduled for individual intakes in $\mathrm{SC}$ attended intake in nearly identical proportion to those scheduled for Access group $\left(\mathrm{X}^{2}(1)=11 ; P>0.73\right)$.

\section{Secondary outcomes Shared decision making}

Baseline scores on the CPS are presented in Figure 3. Results indicated that about $26 \%$ of patients wanted mostly active roles in the decision-making process with a smaller role for the input of the prescriber. Roughly $22 \%$ of patients wanted a primarily passive role, with the doctor having the largest say in decisions about care. The majority of patients, about $52 \%$, wanted a mostly collaborative process with fairly

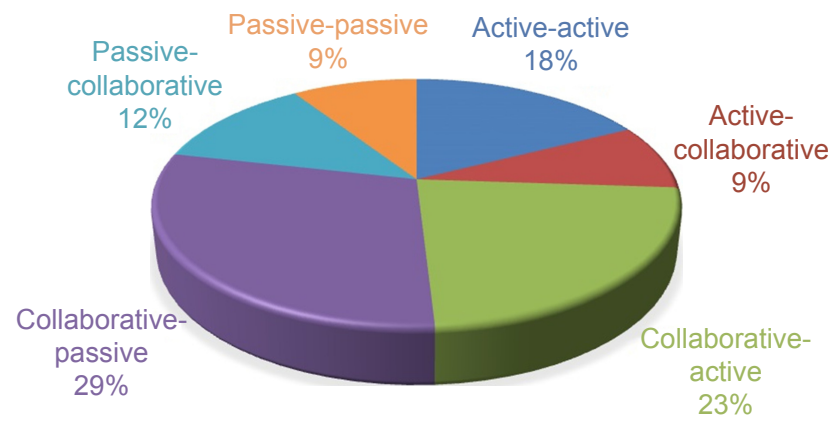

Figure 3 Shared decision-making preference at baseline. equal roles for themselves and the prescribing professional. Examined in another way these data suggest that $91 \%$ of patients in transitional care want to have at least some say in decisions about their treatment.

We examined changes in the CPS from baseline to post-treatment by categorizing patients into two groups: 1) unilateral decision making (wanting to make all or most decisions themselves or wanting the doctor to make all or most decisions); or 2) collaborative decision making (categories in which both the provider and patient had a say in decisions). In $\mathrm{X}^{2}$ analysis, there were not significant differences from baseline to follow-up regarding these preferences $\left(\mathrm{X}^{2}(1)=0.03 ; P>0.78\right)$. Analyzing all categories produced the same result, suggesting that preferences for level of decision making desired were fairly stable in this sample $\left(\mathrm{X}^{2}(5)=5.29 ; P>0.38\right)$.

In addition, we were interested in whether patients and providers came to see communication during visits more similarly on the MPI over time and by treatment group. The mixed-effects regression model examining mean difference on the MPI between patient and provider on ratings of insession SDM parameters indicated a nonsignificant effect of group $(\mathrm{F}(1,272)=0.41 ; P>0.52)$, a significant effect of time $(\mathrm{F}(6,437)=3.70 ; P<0.002)$, and a nonsignificant group-by-time interaction $(\mathrm{F}(6,437)=0.27 ; P>0.55)$. An inspection of means shows that in both groups, patients' and providers' ratings of how the session went got closer over time (Figure 4).

\section{Symptomatology}

We investigated changes in symptomatology over time by treatment group as important background against which to interpret other study results. Results of mixed-effects regression on the BPRS total score indicated no significant effect of group $(\mathrm{F}(1,216)=12 ; P>0.72)$ or group-by-time interaction $(\mathrm{F}(1,216)=04 ; P>0.84)$ but a significant effect of time. Inspection of means indicates that patients improved in terms of symptomatology over time while in treatment at the TCC $(\mathrm{F}(1,133)=3.95 ; P<0.05)$ irrespective of group.

\section{Patient satisfaction and intent to participate in treatment after discharge from the TCC}

Patients at the TCC rated satisfaction as very good. In SC, overall treatment satisfaction was $6.4(\mathrm{SD}=0.87)$, and in $\mathrm{EFC}$ it was $6.1(\mathrm{SD}=1.0)$. Results of a Wilcoxon test indicated that this difference was statistically significant $(\mathrm{Z}=2.85$; $P<0.004)$

Ninety-six percent of patients in EFC and $90 \%$ in SC reported intent/desire to keep their post-TCC appointments 


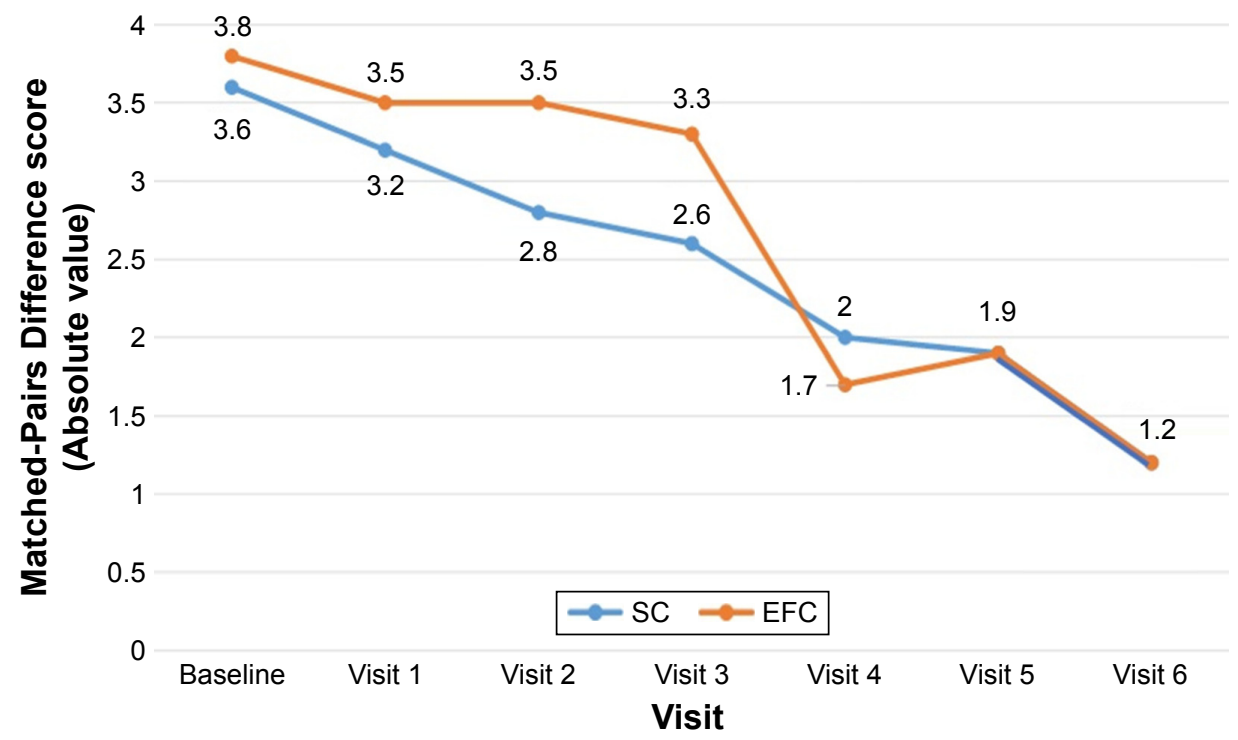

Figure 4 Matched-Pair Difference score time by treatment group.

Abbreviations: EFC, engagement-focused care; SC, standard care.

for mental health care. This was not a significant difference according to Fisher's exact test $(P=0.19)$.

\section{Service utilization}

In the 6 months postdischarge from the TCC, $41 \%$ of the patients in SC and 35\% of the patients in EFC had at least one hospitalization, crisis visit, or incarceration. The difference between groups did not reach statistical significance $\left(\mathrm{X}^{2}(1)=0.49 ; P>0.48\right)$.

\section{Discussion/conclusion}

EFC, which involved getting individuals into treatment rapidly and helping them to communicate better with their provider using an SDM coach, appears to improve subjective quality of life for patients. This improvement may be related to issues such as taking a more active role in their treatment or feeling more comfortable expressing preferences with providers. This finding is consistent with preferences expressed by individuals in transition from inpatient settings to care in the community. ${ }^{11}$ This difference could not be attributed to differential symptom change within the two treatment groups. Both groups improved over time in terms of level of symptomatology and there were no treatment group differences. It is important to note that while treatment satisfaction at the TCC in general was $>6$ on a 7 -point scale, individuals in EFC had slightly lower treatment satisfaction. It may be that focusing on SDM and on getting what you want out of visits with a prescriber created slightly more awareness of dissatisfaction.

There were no differences in engagement for individuals receiving EFC versus $\mathrm{SC}$ on our primary measure of engagement, attending treatment postdischarge from the TCC. However, there was a strong trend for patients in EFC to have higher show rate at subsequent TCC visits than those in SC. Small group differences in engagement may be due to our state-of-the-art SC at the TCC, which focuses on engagement and providing a warm hand off to follow-up services. ${ }^{10}$ It was interesting to find that virtually identical numbers of patients showed up for access group and individual intake when recruitment took place at the hospitals. This indicates that an access group appointment is not a disincentive for people to attend an initial follow-up visit after hospitalization, and the process allows sooner scheduling, accommodating more individuals. Access group could be an important model for overburdened services.

Baseline preferences for SDM vary considerably among patients. However, even in this population in post-acute transitional care, the vast majority of patients want to be either equally involved or have the primary say in decisions about their care. Additional research on ways to make this possible is important. There is almost no research focused on tailoring SDM coaching to the type of decision making preferred by the client. About two-thirds of the patients make use of SDM when available, but session times had to accommodate patient schedules, occurring either before or after visits, for between 15 and 60 minutes depending a lot on patient factors such as time, transportation, and content of session. It is also interesting that patients and providers have more discrepant views regarding their dyadic communication during treatment sessions early in the course of treatment and tended to view sessions more similarly over time. This is 
possibly a consequence of getting to know one another and understanding more about how communications are intended by the other person in the dyad.

There were multiple limitations to the current study. There was a high dropout rate, which is consistent with a population just following acute crisis. Moreover, by recruiting the vast majority of patients from those already coming to the TCC who were likely already more engaged in care, it is likely that the differences between EFC and SC were diminished. Training all clinicians in SDM prior to the trial may have also limited our ability to find group differences. However, many residents and psychiatrists believe that they are doing SDM without fully understanding the impact of the power differential and other factors involved in interactions with their patients. We trained all staff as a minimum of what should occur in standard practice. Overall, EFC was not so different in our TCC except with respect to the important dimension of patient subjective quality of life. The TCC is a state-of-the art treatment program focusing on engagement. The models followed by the TCC in general in comparison to $\mathrm{SC}$ in the community could be investigated in further research. Ways of tailoring SDM to preferences of patients for their level of involvement may be important to investigate in future research.

\section{Acknowledgments}

This work was (partially) supported through a PatientCentered Outcomes Research Institute (PCORI) Pilot Project Program Award (IH-1304-6506) and funding from the Methodist Healthcare Ministries and the Texas Health and Human Services Commission Delivery System Reform Incentive Payment (DSRIP) 1115 Waiver. All statements in this report, including its findings and conclusions, are solely those of the authors and do not necessarily represent the views of the (PCORI), its Board of Governors, or Methodology Committee. Dr John Kliewer will be missed by all who knew him.

\section{Disclosure}

The authors report no conflicts of interest in this work.

\section{References}

1. Olfson M, Marcus SC, Doshi JA. Continuity of care after inpatient discharge of patients with schizophrenia in the Medicaid program: a retrospective longitudinal cohort analysis. J Clin Psychiatry. 2010;71(7):831-838.

2. Omer S, Priebe S, Giacco D. Continuity across inpatient and outpatient mental health care or specialization of teams? A systematic review. Eur Psychiatry. 2015;30(2):258-270.

3. Insel TR. Assessing the economic costs of serious mental illness. Am J Psychiatry. 2008;165(6):663-665.

4. Boyer CA. Meaningful linkage practices: challenges and opportunities. New Dir Ment Health Serv. 1997;1997(73):87-101.
5. Olfson M, Mechanic D, Boyer CA, Hansell S. Linking inpatients with schizophrenia to outpatient care. Psychiatr Serv. 1998;49(7): 911-917.

6. Boyer CA, McAlpine DD, Pottick KJ, Olfson M. Identifying risk factors and key strategies in linkage to outpatient psychiatric care. Am J Psychiatry. 2000;157(10):1592-1598.

7. Dixon L, Goldberg R, Iannone V, et al. Use of a critical time intervention to promote continuity of care after psychiatric inpatient hospitalization. Psychiatr Serv. 2009;60(4):451-458.

8. Susser E, Valencia E, Conover S, Felix A, Tsai WY, Wyatt RJ. Preventing recurrent homelessness among mentally ill men: a "critical time" intervention after discharge from a shelter. Am J Pub Health. 1997;87(2): 256-262.

9. Rosenheck RA, Dennis D. Time-limited assertive community treatment for homeless persons with severe mental illness. Arch Gen Psychiatry. 2001;58(11):1073-1080.

10. Velligan DI, Roberts D, Martinez M, Fredrick MM, Hillner K, Luber P. Following AACP guidelines for transitions in care: the transitional care clinic. Psychiatr Serv. 2016;67(3):259-261.

11. Velligan DI, Roberts DL, Sierra C, Fredrick MM, Roach MJ. What patients with severe mental illness transitioning from hospital to community have to say about care and shared decision-making. Issues Ment Health Nurs. 2016;37(6):400-405.

12. Greenfield S, Kaplan SH, Ware JE Jr, Yano EM, Frank HJ. Patients' participation in medical care: effects on blood sugar control and quality of life in diabetes. J Gen Int Med. 1988;3(5):448-457.

13. Seeman M, Seeman TE. Health behavior and personal autonomy: a longitudinal study of the sense of control in illness. $J$ Health Soc Behav. 1983;24(2):144-160.

14. Stewart M, Brown J. Patient-centredness in medicine. In Elwyn G, Edwards A, editors. Evidence-Based Patient Choice: Inevitable or Impossible? New York, NY: Oxford University Press; 2001: 97-112.

15. Britten N, Stevenson FA, Barry CA, Barber N, Bradley CP. Misunderstandings in prescribing decisions in general practice: qualitative study. Br Med J. 2000;320(7233):484-488.

16. Towle A, Godolphin W, Manklow J, Wiesinger H. Patient perceptions that limit a community-based intervention to promote participation. Patient Educ Couns. 2003;50(3):231-233.

17. Velligan DI, Weiden PJ, Sajatovic M, et al. The expert consensus guideline series: adherence problems in patients with serious and persistent mental illness. J Clin Psychiatry. 2009;70(Suppl 4):5-46.

18. New Freedom Commission on Mental Health. Achieving the promise: transforming mental healthcare in America. Final Report. Rockville, MD; 2003. DHHS Pub. No. SMA-03-3832.

19. Institute of Medicine: Committee on Quality of Healthcare in America. Crossing the Quality Chasm: Aa New Health System for the 21st Century. Washington, DC: National Academies Press; 2001.

20. Institute of Medicine. Improving the quality of healthcare for mental and substance use conditions: quality chasm series. Washington, DC: National Academies Press; 2005.

21. National Consensus Conference on Mental Health Recovery and Mental Health Systems Transformation. 2006; Available from: http://www. mentalhealth.samhsa.gOv/media/ken/pdf/SMAo5-4i29/trifold.pdf. Accessed November 25, 2016.

22. Carpenter WT Jr, Gold JM, Lahti AC, etal. Decisional capacity for informed consent in schizophrenia research. Arch Gen Psychiatr. 2000;57(6): 533-538.

23. Grisso T, Appelbaum PS. The MacArthur treatment competence study. III: abilities of patients to consent to psychiatric and medical treatments. Law Hum Behav. 1995;19(2):149-174.

24. Adams JR, Drake RE, Wolford GL. Shared decision-making preferences of people with severe mental illness. Psychiatr Serv. 2007; 58(2007):1219-1221.

25. Arora NK, Mchorney CA. Patient preferences for medical decision making: who really wants to participate? Med Care. 2000;38(3): 335-341. 
26. De las Cuevas C, Rivero A, Perestelo-Perez L, Gonzales M, Perez J, Penate W. Psychiatric patients' attitudes towards concordance and shared decision making. Patient Educ Couns. 2001;85(3):245-250.

27. Hamann J, Cohen R, Leucht S, Busch R, Kissling W. Do patients with schizophrenia wish to be involved in decisions about their medical treatment? Am J Psychiatry. 2005;162(12):2383-2384.

28. Tanenbaum SJ. Consumer perspectives on information and other inputs to decision making: implications for evidence-based practice. Community Ment Hlt J. 2008;44(5):31-35.

29. Lehman A. A quality of life interview for the chronically mentally ill. Eval Program Plann. 1988;11(1):51-62.

30. Lehman AF. Measures of quality of life among persons with severe and persistent mental disorders. Soc Psychiatry Psychiatr Epidemiol. 1996;31(2):78-88.

31. O'Brien A, Fahmy R, Singh SP. Disengagement from mental health services. Soc Psychiatry Psychiatr Epidemiol. 2009;44(7):558-568.

32. Tetley A, Jinks M, Huband N, Howells K. A systematic review of measures of therapeutic engagement in psychosocial and psychological treatment. J Clin Psychol. 2011;67(9):927-941.

33. Fiorentine R, Anglin MD. Does increasing the opportunity for counseling increase the effectiveness of outpatient drug treatment? Am J Drug Alcohol Abuse. 1997;23(3):369-382.

34. McMurran M, Huband N, Overton E. Non-completion of personality disorder treatments: a systematic review of correlates, consequences and interventions. Clin Psychol Rev. 2010;30(3):277-287.

35. Ventura J, Green MF, Shaner A, Liberman RP. Training and quality assurance with the Brief Psychiatric Rating Scale: 'The drift busters'. Int J Meth Psychiatr Res. 1993;3(4):221-244.
36. Amador XF, Flaum M, Andreasen NC, et al. Awareness of illness in schizophrenia and schizoaffective and mood disorders. Arch Gen Psychiatry. 1994;51(10):826-836.

37. Shapiro S, Tischler GL, Cottler L, et al. Health Services Research Questions, in Epidemiologic Field Methods in Psychiatry. Eaton WW, Kessler LG, editors. Orlando, FL, USA: Academic Press. 1985: 191-208.

38. Hays RD, Spritzer K, McCaffrey DF, et al. The HIV cost and services utilization study (HCSUS) measures of health-related quality of life. RAND Health. 1998;1(2):1-16.

39. Velligan DI, Diamond PM, Mintz J, et al. The use of individually tailored environmental supports to improve medication adherence and outcomes in schizophrenia. Schizophr Bull. 2008;34(3):483-493.

40. Velligan DI, Mintz J, Maples N, et al. A randomized trial comparing in person and electronic interventions for improving adherence to oral medications in schizophrenia. Schizophr Bull. 2013;39(5):999-1007.

41. Degner LF, Kristjanson LJ, Bowman D, et al. Information needs and decisional preferences in women with breast cancer. J Amer Med Assoc. 1997;277(18):1485-1492.

42. Campbell C, Lockyer J, Ladilaw T, MacLeod H. Assessment of a matched-pair instrument to examine doctor-patient communication skills in practicing doctors. Med Edu. 2007;41(2):123-129.

43. Woltmann EM, Wilkniss SM, Teachout A, McHugo GJ, Drake RE. Trial of an electronic decision support system to facilitate shared decision making in community mental health. Psychiat Serv. 2011;62(1): 54-60.
Patient Preference and Adherence

\section{Publish your work in this journal}

Patient Preference and Adherence is an international, peer-reviewed, open access journal that focuses on the growing importance of patient preference and adherence throughout the therapeutic continuum. Patient satisfaction, acceptability, quality of life, compliance, persistence and their role in developing new therapeutic modalities and compounds to optimize

\section{Dovepress}

clinical outcomes for existing disease states are major areas of interest for the journal. This journal has been accepted for indexing on PubMed Central. The manuscript management system is completely online and includes a very quick and fair peer-review system, which is all easy to use. Visit http://www. dovepress.com/testimonials.php to read real quotes from published authors. 